\title{
Pseudomyxoma peritonei: a rare tumour mimicking primary ovarian neoplasia
}

\author{
Cátia Filipa Martins, ${ }^{1}$ Sara Costa, ${ }^{1}$ Pedro Guedes, ${ }^{2}$ Ana Filipa Rafael ${ }^{1}$
}

${ }^{1}$ Department of GynaecologyObstetrics, Centro Hospitalar do Algarve, Portimão, Portugal ${ }^{2}$ Centro Hospitalar do Algarve, Portimão, Portugal

\section{Correspondence to Dr Cátia Filipa Martins, paixaocatia@gmail.com}

Accepted 12 February 2015

\section{CrossMark}

To cite: Martins $C F$, Costa S, Guedes P, et al. BMJ Case Rep Published online: [please include Day Month Year] doi:10.1136/ bcr-2014-209251

\section{DESCRIPTION}

A 66-year-old woman presenting with a 6-month history of abdominal distension and an episode of intestinal obstruction was referred to our department. Clinical examination identified a mass arising from the pelvis and ultrasound evaluation demonstrated a large multicystic complex tumour, approximately $30 \mathrm{~cm}$ in diameter, containing fluid, arising from the right ovary (figure 1). CA125 estimation was $11 \mathrm{U} / \mathrm{mL}$ (normal range $<30.2 \mathrm{U} / \mathrm{mL}$ ). An exploratory laparotomy was performed, revealing free mucin, a normal left ovary and a giant right adnexal mass (figure 2). Accidental rupture during surgery released a copious amount of mucinous material (figures 3 and 4 ) and an enlarged appendix with a pale nodular mass (figure 5) was noted. These findings initially raised the possibility of two synchronous neoplastic lesions. Peritoneal lavage, hysterectomy, bilateral salpingo-oophorectomy, omentectomy and appendicectomy were performed. Histological examination supplemented by immunohistochemical studies (figures 6 and 7) demonstrated that the mass was a mucinous cystadenoma of the appendix (low-grade dysplasia) with pseudomyxoma peritonei (PMPs) and a similar right ovarian borderline tumour of primitive origin in the appendix. The morphology and immunophenotype of the epithelium lining the mucinous cysts in the ovary suggested a gastrointestinal origin $(\mathrm{CK} 20+/ \mathrm{CK} 7+)$. At 10-month follow-up the patient was well with no evidence of recurrence.

PMP is an unusual condition characterised by diffuse collections of gelatinous material in the abdomen and pelvis, and mucinous deposits on the peritoneal surface. The term PMP was originally applied to an intraperitoneal mucinous tumour spread originating from a cystadenoma of the appendix. As the tumour grows within the appendix it is thought to occlude the lumen; mucus accumulates and the appendix itself then ruptures seeding the peritoneum with mucus-producing cells, which continue to proliferate. The condition progresses to intestinal obstruction, which is fatal without treatment. PMP is a rare disease, more frequent in women, and found unexpectedly in approximately 2 in every 10000 laparotomies, where simultaneous disease in the appendix and ovaries may be identified. ${ }^{1}$ Recent consensus has

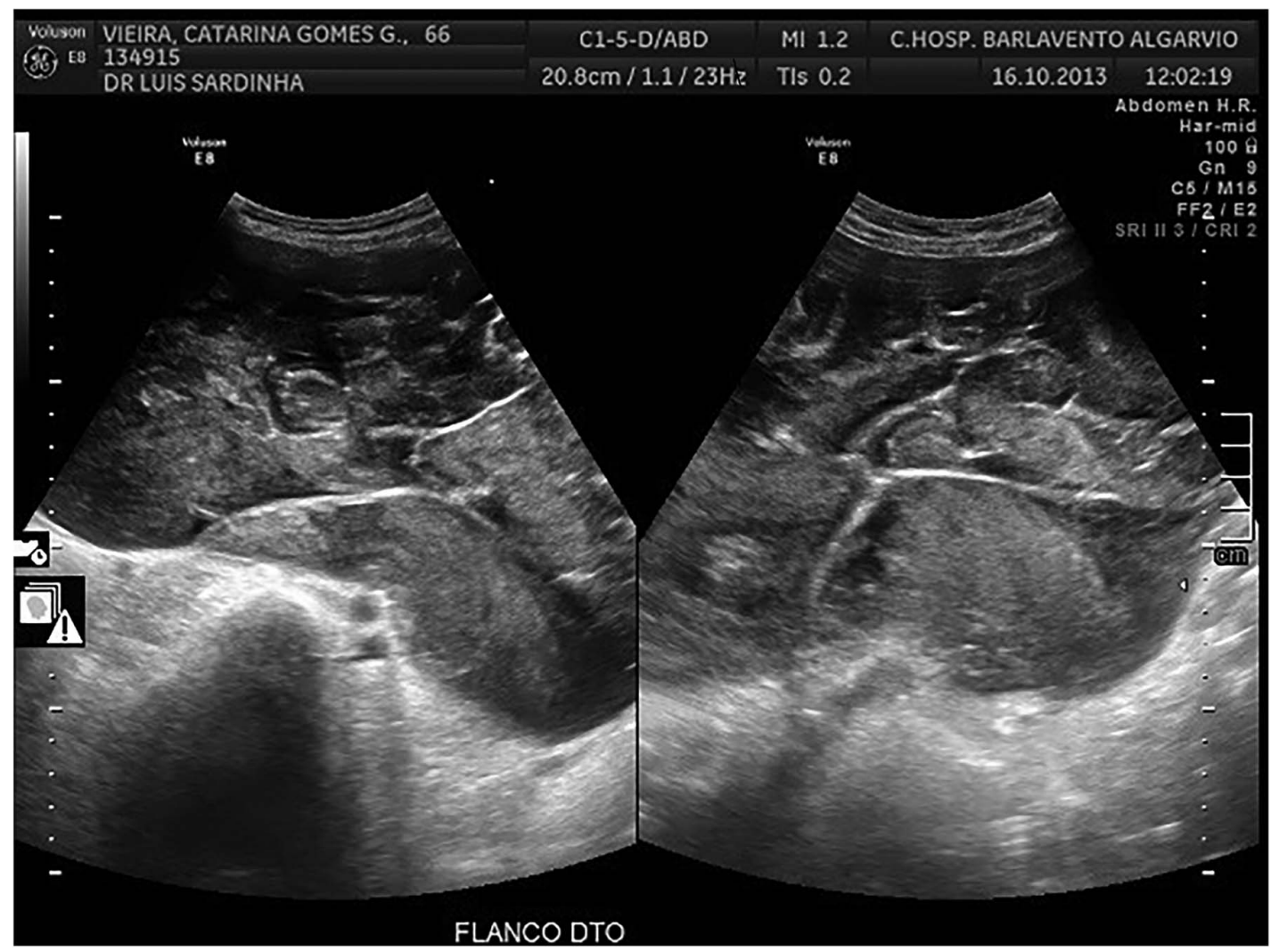

Figure 1 Pelvic ultrasound examination, via transabdominal, showing a giant multicyst mass, full of fluid and apparently some solid areas, with origin in the right ovary. 


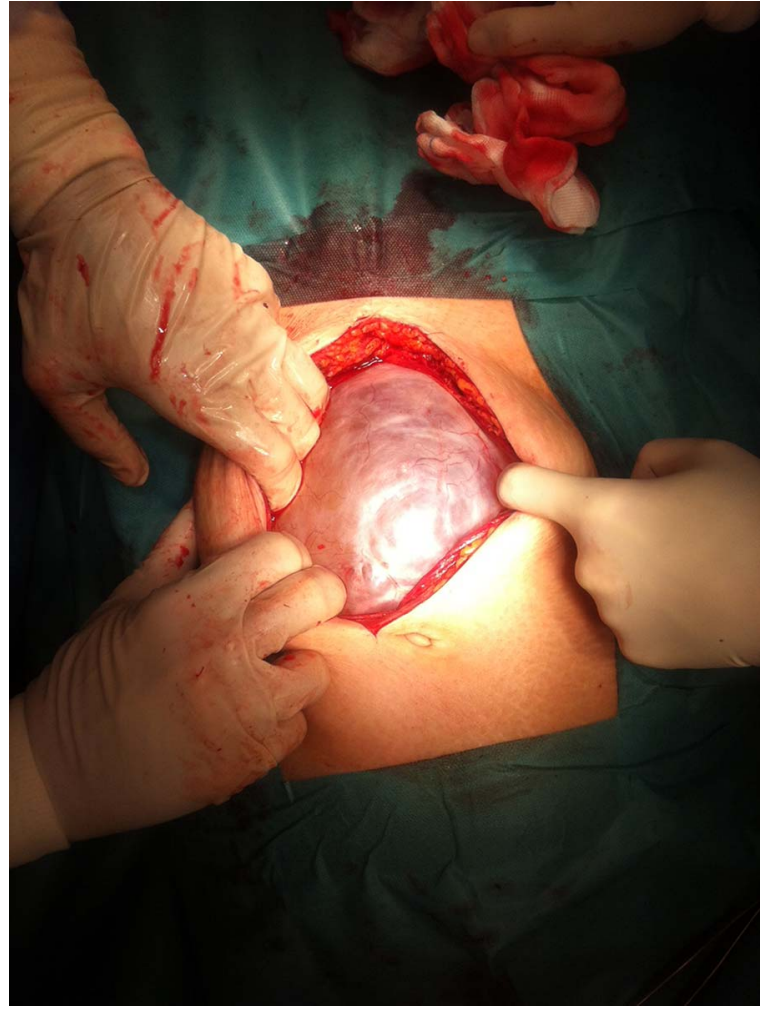

Figure 2 Giant right adnexal mass $(30 \times 22 \times 20 \mathrm{~cm})$, multicystic, similar to borderline ovary mucinous tumours, identified at exploratory laparotomy.

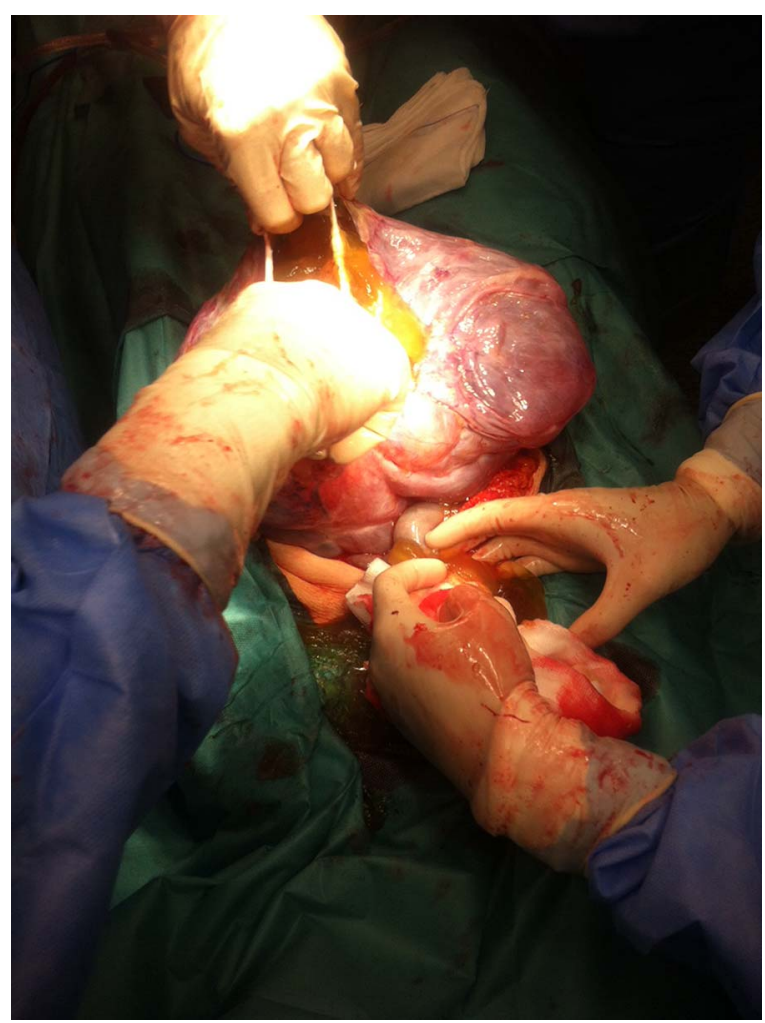

Figure 3 Accidental rupture of the multicystic mass, which was filled with free mucinous material.

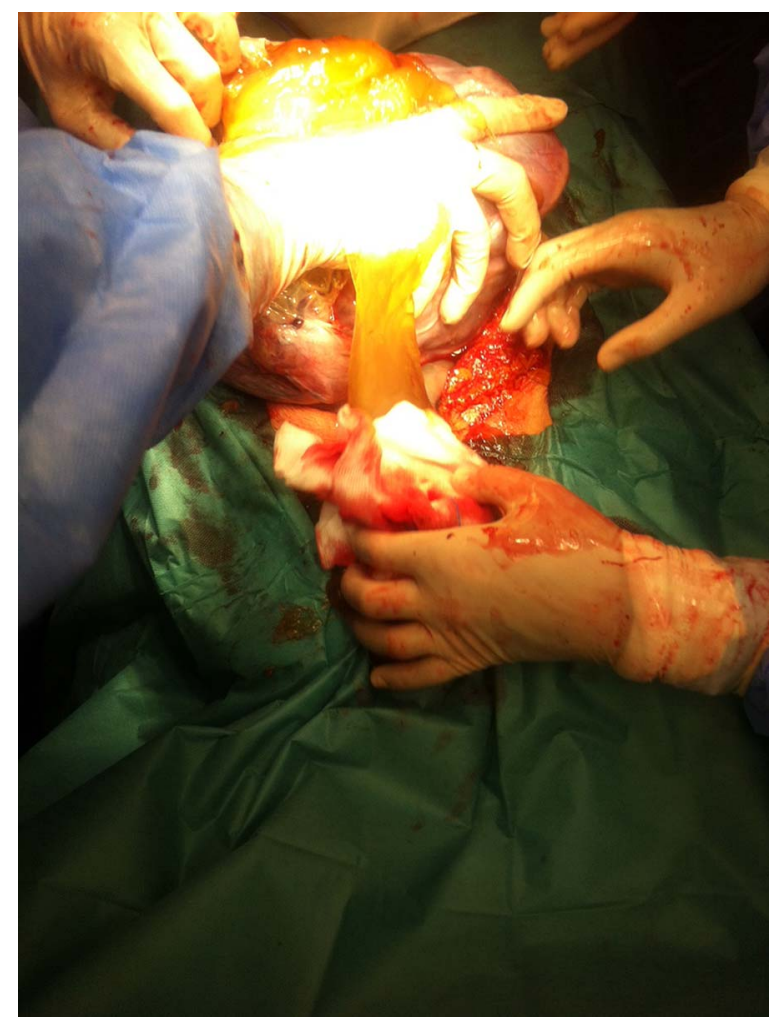

Figure 4 Multicystic mass releasing copious amounts of mucinous material $(3600 \mathrm{~g})$.

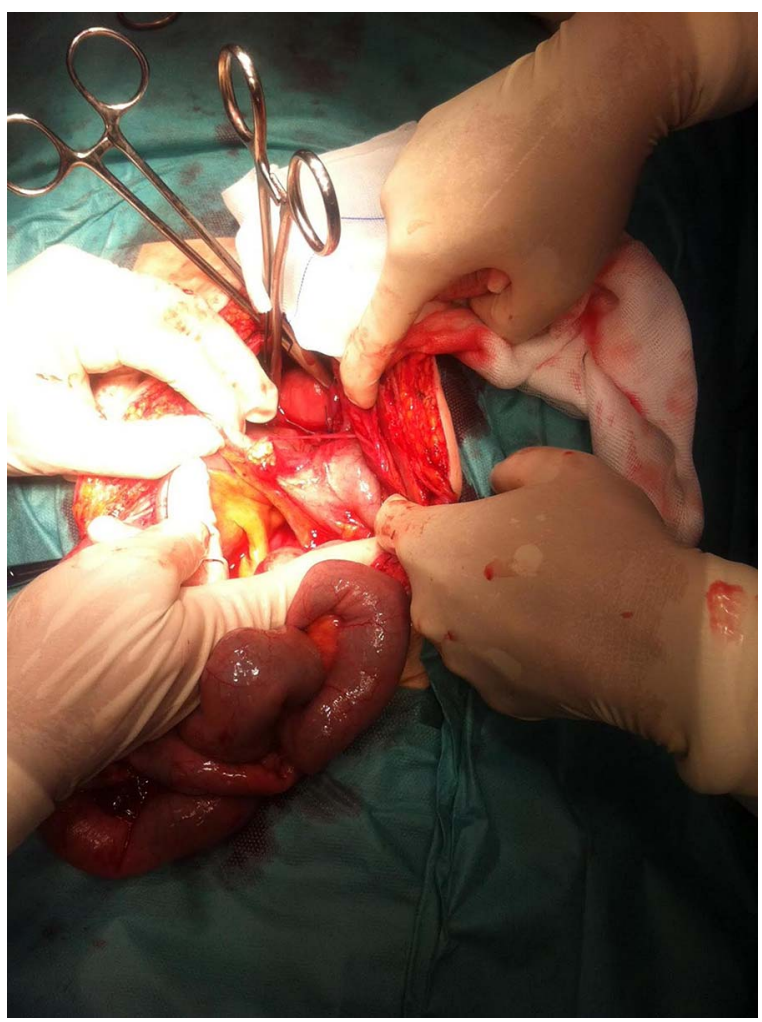

Figure 5 On the right, between fingers, we can see an enlarged appendix with a nodular pale tumour. 


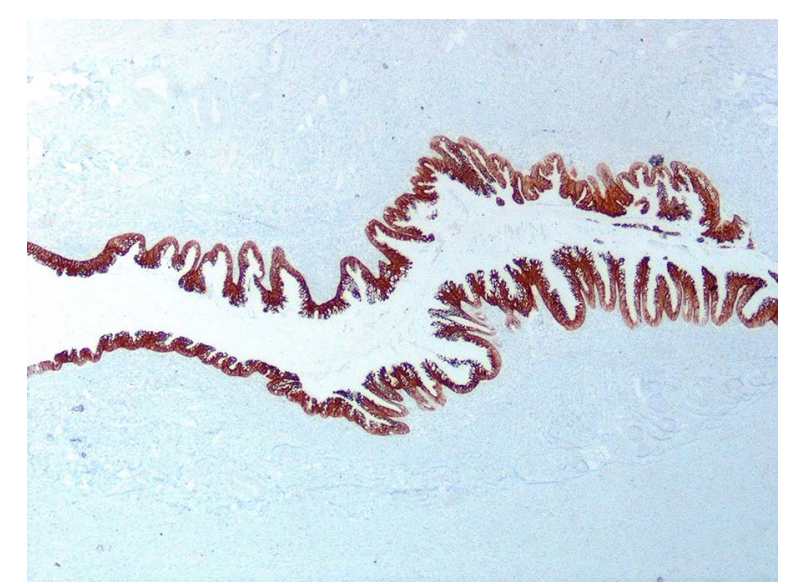

Figure 6 Histological examination of the appendix with immunohistochemical study, identified a mucinous cystadenoma with low-grade dysplasia, extending to all tissue layers and ruptured wall. Positive for K20.

been reached, using immunohistochemical and molecular genetic evidence, indicating that the appendix is the most frequent site of origin; disease in the ovaries probably reflects secondary tumour deposits. ${ }^{2}$ Standard treatment for PMP is repeated surgical debulking for symptomatic disease. This

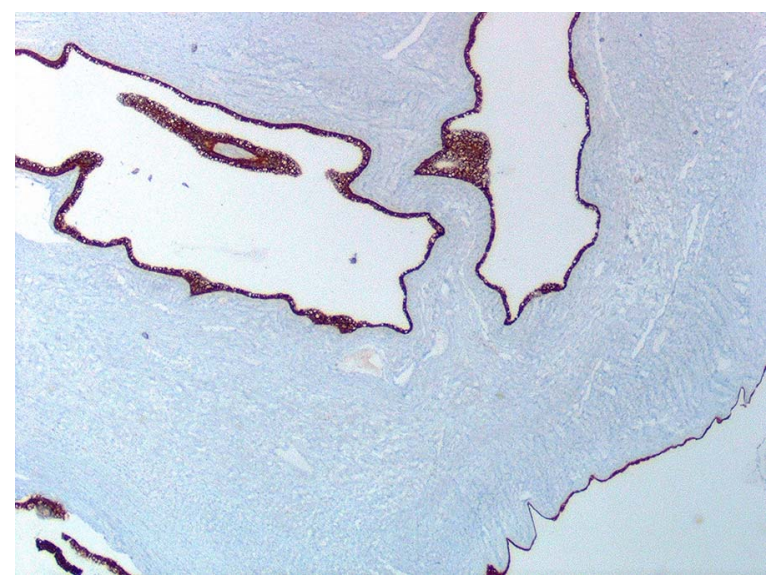

Figure 7 Histological examination of the right ovary with immunohistochemical study reveling a mucinous cystadenoma, with borderline micro focus, positive for $\mathrm{K} 20$ (shown in the figure) and K7, similar to the appendix. treatment is not curative but aims to resect gross disease to limit the accumulation of mucus and ameliorate its pressure effects. In addition, surgery has been combined with adjuvant therapy including external beam radiotherapy, intraperitoneal radioisotopes, intraperitoneal chemotherapy and systemic chemotherapy, to prolong survival. However, evidence remains unclear of the benefit of adjuvant therapy because randomised clinical trials have not been performed. ${ }^{3}$

\section{Learning points}

- Pseudomyxoma peritonea (PMP) is a rare disease characterised by the spread throughout the abdomen of mucinous ascites with peritoneal and omental mucinous implants.

- Patients usually present with an abdominal distension ('jelly belly'), or PMP is diagnosed at abdominal surgery being undertaken for other reasons.

- In most patients with PMP, the appendix is the site of primary tumour; in females, the ovaries are usually also involved due to direct invasion or secondary deposits from the adjacent appendix. The misdiagnosis of a secondary ovarian tumour as a primary neoplasia must be avoided as it will adversely affect surgical management, complementary treatment and prognosis.

- The natural history of PMP is one of indolent but progressive growth, and if left untreated, PMP is fatal. An aggressive approach using radical surgical cytoreduction of all intra-abdominal and pelvic disease and intraperitoneal heated chemotherapy, with the intent to cure, has more recently been advocated by some clinicians. ${ }^{3}$

Competing interests None.

Patient consent Obtained.

Provenance and peer review Not commissioned; externally peer reviewed.

\section{REFERENCES}

1 van Ruth S, Acherman YI, Verwaal VJ, et al. Pseudomyxoma peritonei: a review of 62 cases. Eur I Surg Oncol 2003;29:682-8.

2 Young RH, Gilks CB, Scully RE. Mucinous tumors of the appendix associated with mucinous tumors of the ovary and pseudomyxoma peritonei. A clinicopathological analysis of 22 cases supporting an origin in the appendix. Am J Surg Pathol 1991:15:415-29.

3 Sugarbaker PH. Cytoreductive surgery and perioperative intraperitoneal chemotherapy as a curative approach to pseudomyxoma peritonei syndrome. Tumori 2001:87:S3-5.

Copyright 2015 BMJ Publishing Group. All rights reserved. For permission to reuse any of this content visit

http://group.bmj.com/group/rights-licensing/permissions.

BMJ Case Report Fellows may re-use this article for personal use and teaching without any further permission.

Become a Fellow of BMJ Case Reports today and you can:

- Submit as many cases as you like

- Enjoy fast sympathetic peer review and rapid publication of accepted articles

- Access all the published articles

- Re-use any of the published material for personal use and teaching without further permission

For information on Institutional Fellowships contact consortiasales@bmjgroup.com

Visit casereports.bmj.com for more articles like this and to become a Fellow 